\title{
USO DE JOGOS PARA O ATENDIMENTO A CRIANÇAS COM DIFICULDADES NA ALFABETIZAÇÃO ${ }_{1}$
}

\author{
Andreia Osti ${ }^{2}$ \\ Tatiana Andrade Fernandes de Lucca ${ }^{3}$ \\ Ana Carolina Manfroni ${ }^{4}$
}

\begin{abstract}
RESUMO: Este trabalho, de natureza qualitativa e exploratória, é resultado de um projeto que objetivou proporcionar a crianças que apresentavam atraso em seu processo de alfabetização uma forma diferente e lúdica de aprender a ler e a escrever. Participaram 93 alunos do primeiro ciclo do ensino fundamental, de duas escolas públicas municipais no interior de São Paulo, que não estavam alfabetizados ou que estavam com defasagem na aprendizagem da leitura e escrita. Os alunos foram atendidos uma vez por semana em sessões de até uma hora de duração, por estudantes do curso de Pedagogia. Foram realizadas intervenções em que jogos foram utilizados com o intuito de propor uma intervenção focada na leitura e escrita. Os resultados evidenciaram que as crianças atendidas tiveram progresso em sua aprendizagem. Os participantes do processo demonstraram alegria em terem integrado o projeto, uma vez que suas necessidades e dificuldades foram trabalhadas de forma prazerosa e lúdica.
\end{abstract}

Palavras-chave: Ensino. Didática. Alfabetização. Lúdico. Leitura. Escrita.

\section{THE USE OF GAMES FOR THE CARE OF CHILDREN WITH DIFFICULTIES IN LITERACY}

ABSTRACT: This qualitative and exploratory work is the result of a project that aimed to provide children with a delay in their literacy process a different and playful way of learning to read and write. Participants were 93 students from the first cycle of elementary education, from two municipal public schools in the

\footnotetext{
${ }^{1}$ Agradecimento à Pró-Reitoria de Graduação - PROGRAD/Unesp que financiou o projeto intitulado "Alfabetização mediada por meio de jogos pedagógicos" concedendo duas bolsas as (aos) alunas (os) do curso de Pedagogia da UNESP de Rio Claro, e pela dedicação dos estudantes na confecção dos jogos e materiais pedagógicos durante a disciplina de "Metodologia do Ensino Fundamental: Alfabetização".

2 Doutora em Educação. Docente da Universidade Estadual Paulista “Júlio de Mesquita Filho" (UNESP) Rio Claro-SP/ Brasil. Email: andreia.osti@gmail.com

3 Mestre em Educação. Docente da Educação Básica I da Prefeitura Municipal de Rio Claro-SP/Brasil. E-mail: tatiana.andfer@gmail.com

${ }^{4}$ Graduada em Pedagogia. Mestranda em Educação pela Universidade Estadual Paulista "Júlio de Mesquita Filho" (UNESP). Rio Claro-SP/Brasil. E-mail: carol_manfroni@hotmail.com
} 
interior of São Paulo, who were not literate or who were lagging in reading and writing. The students were attended once a week in sessions of up to one-hour duration, by students of the Pedagogy course. Interventions were performed in which games were used with the purpose of proposing an intervention focused on reading and writing. The results showed that the children attended had progress in their learning. The participants of the process showed joy in having integrated the project, since their needs and difficulties were worked in a pleasant and playful way.

Keywords: Teaching. Didactics. Literacy. Ludic. Reading. Writing.

\section{EL USO DE JUEGOS PARA LA ATENCIÓN A NIÑOS CON DIFICULTADES EN LA ALFABETIZACIÓN}

RESUMEN: Este trabajo, de naturaleza cualitativa y exploratoria, es el resultado de un proyecto que objetivó proporcionar a niños que presentaban retraso en su proceso de alfabetización una forma diferente y lúdica de aprender a leer y a escribir. Participaron 93 alumnos del primer ciclo de la enseñanza fundamental, de dos escuelas públicas municipales en el interior de São Paulo, que no estaban alfabetizados o que estaban con desfase en el aprendizaje de la lectura y escritura. Los alumnos fueron atendidos una vez por semana en sesiones de hasta una hora de duración, por estudiantes del curso de Pedagogía. Se realizaron intervenciones en que juegos se utilizaron con el propósito de proponer una intervención enfocada en la lectura y escritura. Los resultados evidenciaron que los niños atendidos tuvieron progreso en su aprendizaje. Los participantes del proceso demostraron alegría en haber integrado el proyecto, una vez que sus necesidades y dificultades se trabajaron de forma placentera y lúdica.

Palabras clave: Enseñanza. Didáctica. Alfabetización. Lúdico. Lectura. Escritura.

\section{Introdução}

A alfabetização é um tema amplamente pesquisado no campo educacional, sendo muito recorrente em vários trabalhos, no entanto, ainda hoje não há um consenso entre os pesquisadores sobre quais os melhores recursos didáticos para garantir a aprendizagem da leitura e da escrita alfabética por alunos da educação básica. No entanto, podemos afirmar, embasados numa perspectiva interacionista, que há certa aproximação entre alguns autores sobre o tema alfabetização (KLEIMAN, 2001; MONTEIRO; SOARES, 2014; SOARES, 2004) quando estes afirmam que a aquisição da leitura e escrita, na atualidade, deve ser entendida como um processo social, em que a alfabetização é um conceito plural que se refere às práticas sociais de leitura e escrita, envolvendo diferentes práticas sociais, não se restringindo 
mais ao simples domínio do código e às atividades de codificação e decodificação.

Também é fato que o Brasil amarga em sua história o fracasso de inúmeros alunos que saem da escola sem estarem alfabetizados. De acordo com Silva (2007), nos últimos cinquenta anos, o Brasil se configurou como um dos campeões mundiais do fracasso na alfabetização. Segundo dados da Pesquisa Nacional por Amostra de Domicílios (2012), o contingente de pessoas analfabetas no Brasil foi de 12,9 milhões de pessoas. Esses índices evidenciam que a aquisição da leitura e escrita ainda é um problema social para grande parte da população brasileira, sobretudo a população que depende da escola pública.

Mais recentemente, segundo o Instituto Nacional de Pesquisas Educacionais Anísio Teixeira (INEP), em 2015, 13\% dos alunos que cursavam o Ensino Fundamental I tinham distorção idade série no referido ano. No Ensino Fundamental II, 26\% ainda apresentavam um atraso escolar e, no Ensino Médio, $27 \%$ dos estudantes não estavam na série adequada (BRASIL, 2015). Cabe esclarecer que os alunos considerados com distorção idade série, segundo o critério adotado pelo INEP, são aqueles que apresentam atraso de dois anos ou mais em relação à série que cursam e a que deveriam cursar, o que indica que os números nacionais ainda são preocupantes.

As questões envolvendo as dificuldades de aprendizagem das crianças dimensionam a discussão da escola e a sua tarefa em atender a todos os alunos, em suas necessidades e especificidades. Assim, ao observar esses índices relacionados aos resultados dos alunos, especialmente no âmbito da alfabetização, conduz também ao questionamento do fracasso da escola em garantir o direito a estes alunos de pleno acesso e utilização da linguagem oral e escrita. Desse modo, compreende-se que são muitos os fatores envolvidos nesse quadro preocupante, como por exemplo, as estruturas das escolas brasileiras, os processos formativos dos professores, o processo de escolarização anterior do aluno e seu contato com a leitura e escrita no cotidiano. No entanto, há certa notoriedade para os procedimentos metodológicos de ensino da leitura e escrita, que podem contribuir (ou não) para a aprendizagem do aluno. Nesse sentido, compreende-se que a discussão acerca da melhora dos índices de alfabetização no país perpassa também por uma discussão sobre métodos e 
materiais para se alfabetizar.

Frente a essa realidade, referente aos resultados de alunos em avaliações em larga escala, o Governo Federal assume o compromisso de buscar políticas públicas indutoras de transformações significativas na estrutura escolar, nas formas de ensinar, organizar e desenvolver o currículo. Podemos inferir que dentre essas ações propostas encontra-se a ampliação da educação básica obrigatória para nove anos e, mais recentemente, o compromisso formal assumido pelos governos federal, do Distrito Federal, dos estados e municípios de assegurar que todas as crianças estejam alfabetizadas até os oito anos de idade, ao final do 3 o ano do ensino fundamental (BRASIL, 2013).

Como forma de melhor assegurar esse direito à criança, foi criado, em 2012, o Pacto Nacional pela Alfabetização na Idade Certa (PNAIC), que tem como principal objetivo implementar uma formação de professores alfabetizadores que propicie uma minuciosa discussão acerca do processo de alfabetização, de modo que o cenário brasileiro nessa área do conhecimento obtenha melhores índices. Cabe destacar que alguns estudos relacionam uma formação docente inicial deficitária na área da alfabetização como uma das causas para a produção dos quadros de fracasso na aprendizagem na educação básica.

Suba (2012) realizou um estudo junto a estudantes de cursos de Pedagogia de cinco instituições diferentes, investigando qual era o tempo dedicado nos cursos às disciplinas que preparam os pedagogos para o ensino da leitura e escrita na educação básica. De acordo com os resultados da autora, cerca de três a quatro disciplinas são dedicadas à discussão da aprendizagem da leitura e escrita nos cursos de formação. Suba (2012) também investigou junto aos alunos dessas instituições se consideravam-se preparados para assumir uma turma de alfabetização quando concluíssem o curso de Pedagogia e, dos dezesseis participantes, apenas três se sentiam preparados para assumir esta tarefa.

Em consonância, Libâneo (2013) também considera que seja necessário discutir os cursos de formações iniciais, especialmente os de Pedagogia, no âmbito do tempo dedicado às disciplinas que preparam os pedagogos para o ensino na educação básica e ressalta que “[...] há pouca preocupação com o que e como ensinar, mostrando insuficiência de 
conhecimentos ligados à formação inicial” (p. 79). Assim, o autor entende que há uma dissociação entre os conteúdos da educação básica e as metodologias de ensino, que torna o professor da educação básica despreparado para assumir sua tarefa.

Logo, o PNAIC é um processo de formação criado para discutir, junto aos professores alfabetizadores, tanto os conteúdos pertinentes ao ciclo de alfabetização, como os meios de trabalhá-los, isto é, diferentes e diversificadas atividades. O Pacto Nacional pela Alfabetização na Idade Certa (BRASIL, 2013) é embasado por quatro princípios centrais em que se considera: 1) o Sistema de Escrita Alfabética é complexo e exige um ensino sistemático e problematizador; 2) o desenvolvimento das capacidades de leitura e de produção de textos ocorre durante todo o processo de escolarização, mas deve ser iniciado logo no início da Educação Básica, garantindo acesso precoce a gêneros discursivos e de circulação social e a situações de interação em que as crianças se reconheçam como protagonistas de suas próprias histórias; 3) os conhecimentos oriundos das diferentes áreas podem e devem ser apropriados pelas crianças, de modo que elas possam ouvir, falar, ler, escrever sobre temas diversos e agir na sociedade; 4) a ludicidade e o cuidado com as crianças são condições básicas nos processos de ensino e de aprendizagem.

Em relação a esse último princípio - a ludicidade - há nos materiais didáticos e pedagógicos que foram distribuídos pelo PNAIC às escolas e utilizados na capacitação dos professores alfabetizadores vários jogos pedagógicos de apoio à alfabetização. O objetivo do uso de jogos em sala de aula é apontado, nesses materiais, como um recurso importante ao processo de alfabetização, uma vez que os jogos possibilitam articular diversas áreas do conhecimento, permitem a participação de todas as crianças, independente de seus impedimentos e dificuldades, oportunizando ao professor formar agrupamentos de acordo com os conhecimentos dos alunos. Nesse material, o jogo consta como atividade permanente, que pode ser coletiva ou individual, deve estar no planejamento do professor e é considerado, para além de uma atividade lúdica, uma atividade específica, que auxilia e direciona a intenção do professor no planejamento de atividades de leitura e escrita para a alfabetização.

Outra medida tomada pelo governo foi a criação da Base Nacional Comum Curricular - 
BNCC - em 2015 (BRASIL, 2015), definida como uma orientação curricular que especifica todos os conteúdos essenciais que os alunos da educação básica devem aprender em cada ano e etapa escolar. A terceira e última versão do documento foi homologada em dezembro de 2017 pelo Conselho Nacional de Educação e, atualmente, as escolas já estão passando por uma fase de reajustes em seus currículos para se adaptarem ao documento. Espera-se que a BNCC seja implantada definitivamente até 2020. A implantação da BNCC conta com um processo de formação contínua dos professores e revisão dos materiais didáticos para que se adequem à Base, porém, no documento, não é mencionado o uso de jogos como ferramenta pedagógica, tampouco a sua disponibilização, como foi feito no PNAIC.

Uma das providências tomadas como forma de adequação à BNCC foi a criação do Programa Mais Alfabetização (BRASIL, 2018), em março de 2018, que se constitui em um programa de acompanhamento de alunos do primeiro e segundo ano do ensino fundamental que possuem defasagem em seus processos de aprendizagem de leitura, escrita e matemática. Na rede municipal onde foi realizada esta pesquisa, esse acompanhamento será feito por voluntários, não necessariamente formados em pedagogia e escolhidos por meio de um processo seletivo simplificado, dentro da sala de aula, e será responsabilidade do professor definir as atividades que serão feitas e supervisionar o voluntário.

A maior mudança da BNCC para o PNAIC é o tempo destinado para a alfabetização. Como já dito, no PNAIC, a criança deve ser alfabetizada até o final do terceiro ano do ensino fundamental. Porém, com a BNCC, o período de alfabetização deve ser consolidado ao final do segundo ano. É válido ressaltar que a BNCC defende que o processo de alfabetização deve ser iniciado no primeiro ano do ensino fundamental, mas que a criança deve ter contato com o universo da leitura e da escrita desde a educação infantil.

Desse modo, compreende-se que os jogos, quando direcionados para a área de linguagens, podem trazer inúmeras contribuições para o processo de aprendizagem da criança, pois permitem o trabalho com conteúdos específicos da alfabetização, como por e exemplo, a reflexão acerca das propriedades do sistema de escrita alfabética; o significado das palavras e sua estrutura e ainda mobilizam o interesse e a atenção da criança. Fernandes e 
Osti (2016) realizaram uma pesquisa acerca dos jogos específicos distribuídos às escolas participantes do PNAIC, elencando as especificidades trabalhadas pelos jogos, principalmente as habilidades que os alunos precisam adquirir sobre o sistema de escrita alfabético, tão importante no período inicial da alfabetização. As autoras demonstraram como esses recursos podem contribuir para o planejamento docente.

Especificamente acerca dos jogos, Piaget (1998) discorre sobre a relação entre o desenvolvimento da cooperação entre os alunos em atividades em grupo e a construção do conhecimento, afirmando que são necessárias, para a constituição da razão, as relações cooperativas entre alunos. Assim, segundo o autor, os jogos podem configurar-se como estas atividades em grupos que vão possibilitar a iniciativa pelo aluno; o desenvolvimento da independência intelectual sobre seus membros; o desenvolvimento do controle mútuo e da reciprocidade e também ações de disciplina e esforço pessoal para se atingir o objetivo proposto.

De acordo com Leal et al. (2008), o jogo constitui uma das formas de tornar o ensino da alfabetização mais eficaz e estimulante. Consideram que ele alia o prazer e o divertimento à aprendizagem, e quando direcionados para a alfabetização e o ensino da língua materna, tornam o processo de aprendizagem revestido de significado, uma vez que integram o prazer e o aprender, bem como a interação com o outro. Além disso, outros autores (FURTADO, 2004; KISHIMOTO et al., 2011; MACEDO; PETTY; PASSOS, 2005; SANTOS 2011) também ressaltam a relevância dos jogos para o processo de desenvolvimento do sujeito e, consequentemente, para sua aprendizagem, ao salientar que tal recurso contribui para o desenvolvimento da atenção, do raciocínio lógico, memória, descentração do pensamento, desenvolvimento da argumentação, a capacidade de se colocar e compreender o ponto de vista do outro, bem como propicia a capacidade de desenvolver seu próprio ponto de vista. Ainda se compreende que os jogos também são ferramentas úteis no trabalho com o processo de interação e socialização dos alunos.

Em relação ao processo específico da alfabetização, os jogos podem ser recursos relevantes para um ensino sistematizado da língua escrita, principalmente aqueles que têm 
como foco alguns aspectos do Sistema de Escrita Alfabética, pois auxiliam os alunos a consolidarem tal aprendizagem, necessária para que se tornem plenamente alfabetizados. Os jogos direcionados para o trabalho com a linguagem permitem que as crianças compreendam algumas especificidades da língua, que não se restringem apenas às propriedades do sistema de escrita, mas dizem respeito à ampliação do vocabulário, ao trabalho com o significado das palavras (semântica) e à estrutura das palavras (morfologia).

Kishimoto et al. (2011) investigaram as contribuições dos jogos para o processo de alfabetização e letramento e enfatizaram que os jogos apresentam contribuições para o processo de aprendizagem, sobretudo porque possibilitam aos estudantes desenvolverem uma visão positiva da escola devido às atividades lúdicas realizadas e que a inserção dos jogos no ensino fundamental permite que sejam utilizados como uma ferramenta para o letramento. Luna (2008) nesse sentindo aborda que, apesar de alguns docentes considerarem que os jogos, muitas vezes, podem não contribuir no contexto educacional, por ser um instrumento que pode provocar a dispersão e a desatenção dos alunos, o jogo, ao contrário do que pensam, "pode estimular, 'convidar' a criança a prestar atenção, a se concentrar para vencer, estendendo esse valor para outras atividades escolares" (p. 112).

Silveira (2004) desenvolveu uma pesquisa na qual analisou a relação entre o jogo e a compreensão leitora e afirmou que as condutas dos sujeitos no jogo têm relação com as condutas adotadas por eles para compreender o que leem. Além disso, também enfatizou que os jogos permitiram que as crianças demonstrassem interesse na atividade, o que reforça o valor do jogo, como atividade direcionada para a aprendizagem no contexto escolar.

Assim, compreende-se que o estudo dos jogos tem diferentes perspectivas teóricas, como por exemplo, a pedagógica, a psicológica, a filosófica, a sociológica e a psicopedagógica, sendo que cada uma destas vertentes analisa uma perspectiva diferente acerca da relação do sujeito com este instrumento cultural, que são os jogos. Desse modo, neste estudo parte-se do princípio da aplicabilidade dos jogos no processo de alfabetização, sendo um instrumento facilitador do ensino para o professor e possibilitador da aprendizagem para o aluno.

Além disso, o desenvolvimento do estudo, além de evidenciar as contribuições dos 
jogos para a aprendizagem, também expõe a questão da formação docente inicial e os meios de ensinar na educação básica. Sabe-se, por meio de pesquisas, que a inserção dos jogos em sala de aula ainda enfrenta algumas resistências por parte dos professores, que dentre as justificativas indicam, por exemplo, a falta de formação para a utilização deste tipo de material (SILVEIRA, 2016), a quantidade de alunos na turma e a dificuldade na organização da proposta para atender a todos (LUCCA, 2018) e a indisciplina gerada em sala de aula quando este tipo de atividade é proposta. Assim, no desenvolvimento deste projeto, foi também trabalhado com as estudantes do curso de Pedagogia os conteúdos inerentes ao ciclo de alfabetização e os meios de desenvolver o trabalho junto aos alunos da educação básica, tendo o jogo com um dos recursos possíveis para o atendimento das dificuldades de aprendizagem.

Neste estudo, portanto, parte-se do princípio de que os jogos podem ser instrumentos importantes no processo de aprendizagem inicial da leitura e da escrita, trabalhando de modo direcionado com as especificidades da língua. No entanto, reconhece-se que essa não pode ser a única estratégia a ser utilizada no processo de alfabetização, que exige a inserção de outras atividades e direcionamentos, como, por exemplo, o contato e leitura de diversos gêneros textuais, as escritas de autoria da própria criança, os exercícios de escrita de textos e reescrita, enfim, uma série de atividades que permitam trabalhar diferentes habilidades e conteúdos. Porém, acerca do processo da aprendizagem da leitura e escrita inicial, compreende-se que os jogos têm muitos aspectos contributivos para a organização deste processo de ensino, pelo professor.

Partindo dessa premissa, de que o processo de aprendizagem deve ser significativo, prazeroso e integrar conhecimento com a interação e que é fator primordial da Educação a garantia ao ensino de qualidade e iguais oportunidades de aprendizagem, este projeto surge no intuito de proporcionar o atendimento específico de alunos do ensino fundamental com dificuldades em seu processo de alfabetização, oferecendo-lhes assistência e atendimento educacional especializado. É também objetivo do projeto abordar problemas da prática pedagógica e contribuir para a prática docente, especialmente dos alunos do curso de pedagogia, no intuito de ensinar outras formas para trabalhar, como, por exemplo, se 
apropriando de jogos como um instrumento para a aprendizagem.

De forma geral, objetivou-se atender alunos do primeiro ciclo do ensino fundamental que não estão alfabetizados ou que estejam com defasagem na aprendizagem da leitura e escrita e proporcionar a eles uma forma diferente e lúdica de aprender a ler e a escrever. Especificamente, buscou-se inserir a ludicidade como componente do processo de aprendizagem da leitura e escrita e utilizar jogos pedagógicos para a construção da aquisição do sistema de escrita alfabética. Considerando que cabe à escola garantir a todos os seus alunos oportunidades de aprendizagem que possam promover continuamente avanços escolares, em observância aos princípios e diretrizes estabelecidos na Lei de Diretrizes e Bases da Educação Nacional (LDB no. 9.394/96) este trabalho promove uma reflexão acerca da importância de procedimentos e estratégias diferenciadas para o ensino da leitura e escrita, no caso específico, o uso de jogos pedagógicos.

\section{$O$ contexto da pesquisa}

Realizou-se um trabalho de intervenção junto aos alunos de duas escolas da rede Municipal de uma cidade pertencente à mesorregião de Piracicaba, no interior de São Paulo, que foram diagnosticados por seus professores e pela coordenação da escola como crianças em situação de atraso escolar por não estarem alfabetizadas ou por apresentarem defasagem na aprendizagem da leitura e escrita. $O$ atendimento foi autorizado pelos responsáveis e teve aprovação do Comitê de Ética em Pesquisa com Seres Humanos.

O fato de essas crianças apresentarem atraso na aquisição da leitura e escrita repercute em outros conteúdos escolares, implica na dificuldade de adquirir novos conhecimentos e de ter um pleno desenvolvimento de suas habilidades e capacidades, o que também os torna mais vulneráveis a desenvolver comportamentos e sentimentos negativos, por ter consciência de seu atraso e de sua dificuldade para aprender. A partir do apontamento dos professores e coordenadores da escola, buscou-se promover ações inclusivas e educativas desenvolvidas mediante a necessidade da instituição escolar, visando o pleno desenvolvimento do aluno atendido. 
Didaticamente foram realizadas atividades diferenciadas, com o foco em jogos pedagógicos voltados especificamente para a alfabetização, leitura e escrita. Os alunos eram atendidos uma vez por semana, durante todo o ano letivo, em sessões de até uma hora de duração. Metodologicamente foram utilizados jogos pedagógicos, tal como bingo, batalha silábica, trilha silábica e ortográfica, dentre outros. Cabe destacar que durante o atendimento dos estudantes foram criados e produzidos diferentes jogos pedagógicos e materiais para leitura, material este confeccionado por estudantes de pedagogia com base nos conteúdos a serem ensinados para as crianças atendidas, visando aperfeiçoar o processo de alfabetização e letramento de alunos do primeiro ciclo do ensino fundamental.

\section{Participantes}

Foram atendidos 47 estudantes em 2016 e 46 alunos em 2015, totalizando 93 alunos, de ambos os sexos, do 20 ano do primeiro ciclo do ensino fundamental, que não estavam alfabetizados ou que estavam com defasagem na aprendizagem da leitura e escrita. As crianças foram indicadas pelos professores da escola e pela coordenação, uma vez que, em comparação aos demais alunos, apresentavam muita defasagem.

\section{Procedimento de atendimento e produção dos dados}

Os atendimentos foram semanais, com duração de duas horas para cada grupo de criança atendida, e foram realizados durante dois anos. As crianças foram separadas em pequenos grupos, até cinco alunos, de acordo com suas dificuldades, em alguns momentos foram feitos atendimentos individuais visando uma sistematização voltada para a dificuldade específica da criança. Todas as atividades foram planejadas buscando despertar na criança a vontade para aprender e a busca pelo enfrentamento de sua dificuldade. Foram, como já exposto, planejadas atividades lúdicas, o que inclui a confecção de jogos pedagógicos diferenciados.

Antes de iniciar o atendimento, foi realizada com todas as crianças uma atividade pedagógica em que se avalia o nível de sua escrita e leitura, realizada por meio de ditado de campo semântico, escrita espontânea e leitura. Com base nesses dados os planejamentos 
foram definidos e realizadas as atividades de cada atendimento.

\section{Resultados e discussão}

Os alunos foram avaliados a cada dois meses (em média), para a verificação de como estava o progresso (ou não) e analisar a evolução de sua escrita e autonomia na leitura. Todos os alunos iniciaram o atendimento na hipótese pré-silábica da escrita. Cabe esclarecer que foram utilizadas as definições propostas por Ferreiro (1985) para analisar a escrita do grupo. De acordo com a referida autora, as hipóteses de escrita são descritas da seguinte forma: présilábica (PS) quando a criança não registra a pauta sonora. A hipótese silábica sem valor (SSV) ocorre quando a letra não corresponde ao valor sonoro e silábica com valor (SCV) ocorre quando a letra registrada tem correspondência sonora. Na fase silábica-alfabética (SA), há uma maior correspondência entre as letras da palavra com o que foi escrito. Na última hipótese chamada de alfabética $(\mathrm{A})$, a escrita apresenta um número maior de letras, havendo a correspondência entre a letra e os fonemas ouvidos, mas pode ainda não haver domínio das regras ortográficas da língua. Durante o processo de atendimento foram realizadas intervenções trimestrais e feitas avaliações para o acompanhamento dos resultados, tal como apresentado no Quadro 1

Quadro 1 - Avaliação do nível da escrita

\begin{tabular}{|c|c|c|c|c|c|c|}
\hline \multirow{2}{*}{ Avaliações } & \multicolumn{5}{|c|}{ Número de crianças em cada hipótese de escrita } & \multirow{2}{*}{$\begin{array}{c}\text { Total de crianças } \\
\text { atendidas }\end{array}$} \\
\hline & PS & SSV & SCV & SA & A & \\
\hline 10 & 08 & 57 & 22 & 06 & -- & \multirow{4}{*}{93} \\
\hline 20 & 05 & 41 & 24 & 19 & 04 & \\
\hline 30 & 03 & 6 & 53 & 14 & 17 & \\
\hline 40 & -- & 3 & 1 & 13 & 76 & \\
\hline
\end{tabular}

Fonte: Elaborado pelas autoras. Dados de pesquisa

O Quadro 1 mostra a evolução dos grupos atendidos, o que evidencia a individualidade, uma vez que nem todos os alunos conseguiram chegar à fase alfabética da escrita. Em termos numéricos, dos 93 alunos que iniciaram o atendimento como PS, após dois 
meses e realizada a primeira avaliação, 08 estavam PS, 57 SSV, 22 SCV e 06 SA. Na segunda avaliação é possível observar que houve uma diminuição de alunos SSV de 57 para 41 e aumento dos SCV (de 22 para 24), SA (de 06 para 19) e A (04). Esse último dado mostra evolução uma vez que na primeira avaliação nenhum aluno era alfabético. A terceira avaliação, ocorrida no terceiro trimestre, teve um maior número de alunos SCV (53) e de alunos alfabéticos (17). Na última avaliação, ocorrida próximo do término do ano letivo, observa-se uma maioria de alunos alfabéticos (76) e silábicos-alfabéticos (13) não havendo mais nenhum aluno pré-silábico.

É fato que a evolução dos alunos não depende unicamente do atendimento, uma vez que os mesmos estavam em sala de aula regular e eram acompanhados pelo professor da sala, no entanto, convém destacar a importância do trabalho com jogos, tal como proposto aqui, uma vez que se percebeu, durante os atendimentos, que os jogos propiciaram aos estudantes uma maior percepção dos fonemas e melhor entendimento da formação de palavras, bem como o reconhecimento delas. Como forma de melhor visualizar essa afirmativa, a Figura 1 mostra as atividades de uma das crianças atendidas que foi a que mais apresentou evolução durante o ano letivo, pois de pré-silábica chegou à hipótese de escrita alfabética, ou seja, sua escrita corresponde alfabeticamente com os fonemas, mesmo que ainda não se aproprie das regras e normas ortográficas.

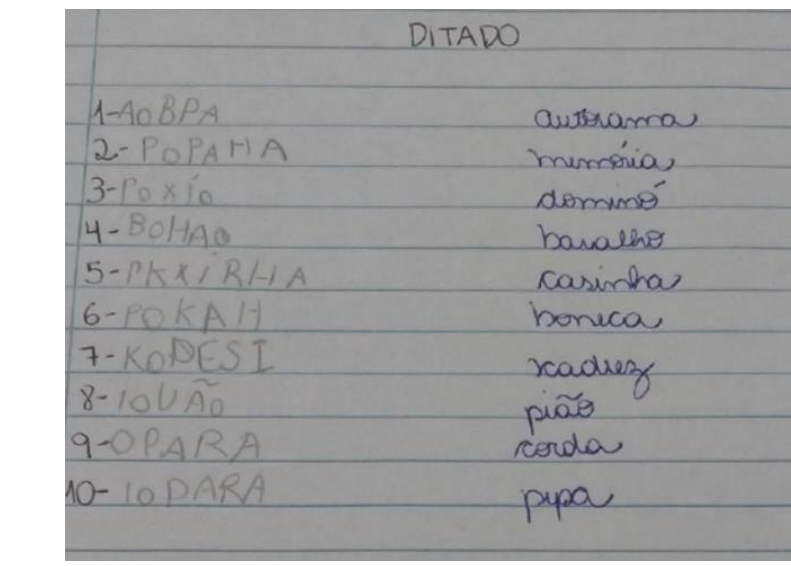

Figura 1 - Ditado semântico - brinquedos - avaliação inicial. Fonte: arquivo documental do projeto

A escrita pertence a uma aluna de nove anos que cursava o 20 ano do Ensino Fundamental e, segundo a escola, não conseguia acompanhar a turma regular a qual pertencia 
em decorrência de sua dificuldade para ler e escrever. Sua escrita é relativa a um ditado diagnóstico que compreende uma lista de dez palavras, cujo campo semântico se relaciona a brincadeiras / brinquedos. Como se pode observar, não é possível fazer uma leitura da escrita dessa criança quando não se conhece a lista das palavras que foram ditadas nem o contexto desta escrita. Em sua produção há uma prevalência, em quase todas as palavras, do uso das letras " $A$ ", " $P$ " e "O", letras estas que fazem parte de seu nome.

Como exposto anteriormente, foram trabalhadas diferentes metodologias, com prevalência da questão lúdica. Abaixo apresentam-se dois jogos que foram confeccionados pela turma do curso de Pedagogia da UNESP, campus de Rio Claro, durante o curso da disciplina "Metodologia do Ensino Fundamental: Alfabetização", sob responsabilidade de uma das autoras deste artigo, com o objetivo de contribuir para o trabalho com as crianças atendidas.

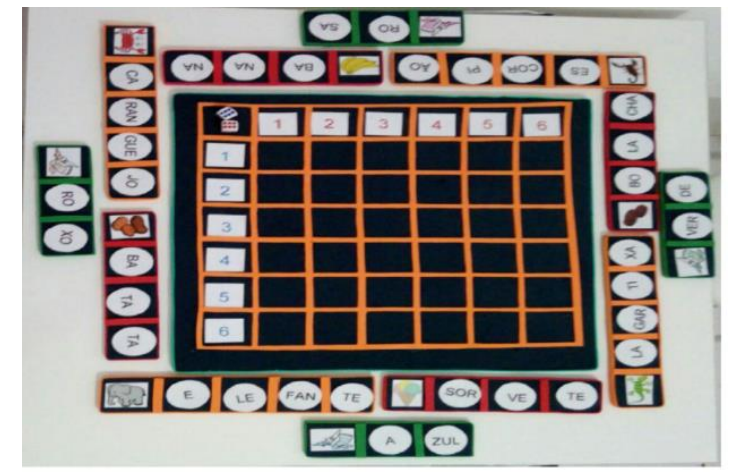

Figura 2 - Jogo Batalha silábica.

Fonte: arquivo documental do projeto.

Esse jogo é trabalhado em duplas e as crianças precisam preencher todos os espaços com as sílabas correspondentes para conseguir formar o nome da figura sorteada. No outro jogo (Figura 3) que também foi confeccionado pelos alunos do curso de pedagogia, as crianças são desafiadas, a partir do sorteio de uma placa, a formar quantas palavras forem possíveis. Ganha a dupla ou grupo que formar o maior número de palavras no menor tempo. Por exemplo, na primeira placa, à esquerda, com as letras “ $A, J, P, L, A, T, N, E, O$ ” é possível formar as palavras: papel, planta, lata, pente, lente, Japão, janela, planeta, loja, dentre outras. 


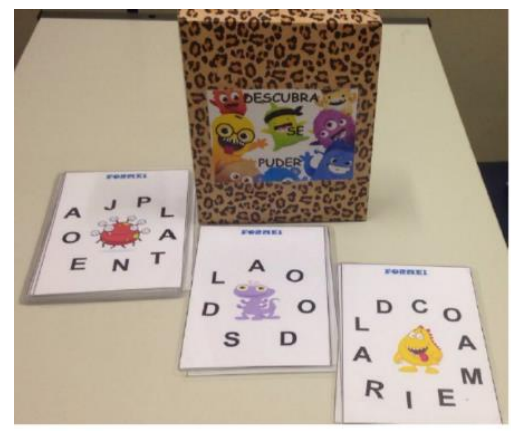

Figura 3 - Jogo descubra se puder. Fonte: arquivo documental do projeto

É interessante descrever que esses jogos, quando trabalhados nos atendimentos, tornam as crianças atendidas muito interessadas, uma vez que são jogos não comercializados, portanto elas não conhecem seu conteúdo e nem imaginam quais são as regras para brincar. Ao mesmo tempo, o material com que são feitos desperta a curiosidade, pois são coloridos, bem diagramados e alegres. Há uma preocupação muito grande, durante o processo de planejamento dos jogos com as turmas do curso de pedagogia, com a questão da segurança da criança (em manipular objetos que possam machucar), deste modo, os alunos são orientados a confeccionar os jogos com materiais que possam ser constantemente manuseados, com maior durabilidade e, além disso, considerem sua função relativa ao conteúdo que precisa ser trabalhado. Nesse caso, o conteúdo direciona-se à aquisição da leitura e escrita. Na continuidade ao atendimento da criança, realizou-se outra avaliação no terceiro bimestre, apresentada na Figura 4.

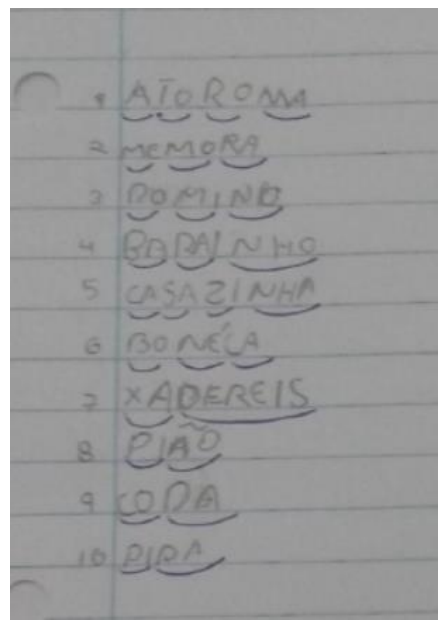

Figura 4 - Ditado semântico - brinquedos - avaliação 3ํ bimestre.

Fonte: arquivo documental do projeto. 
Na produção da Figura 4, nota-se que a aluna conseguiu evoluir em sua escrita, principalmente por ser possível fazer a leitura das palavras escritas sem precisar do registro de apoio (autorama, memória, dominó, baralho, casinha, boneca, xadrez, pião, corda e pipa). Também se observa que alguns erros cometidos anteriormente foram superados, tal como: na palavra "dominó", "casinha" (no ditado anterior tinha registrado a sílaba "nha" como "ra" - casira - e, neste ditado, escreveu a última sílaba da palavra corretamente) e na palavra "xadrez", que embora não tenha escrito da maneira convencional, a forma como escreveu se aproximou bastante do aspecto auditivo. Percebe-se aqui a tentativa de adequação da escrita com a correspondência oral. Na análise de sua produção pode-se observar que a escrita da aluna se aproxima da hipótese alfabética, contudo ainda há ausência de algumas letras (autorama, corda) e acréscimo de outras (xadereis).

O trabalho interventivo continuou e na última avaliação - Figura 5 - percebe-se que na escrita das últimas palavras (uva, figo, caqui, melão, amora, goiaba e jabuticaba) sua produção correspondeu à palavra ditada. Nas demais palavras houve algumas trocas em decorrência da dificuldade ortográfica (tal como em framboesa).

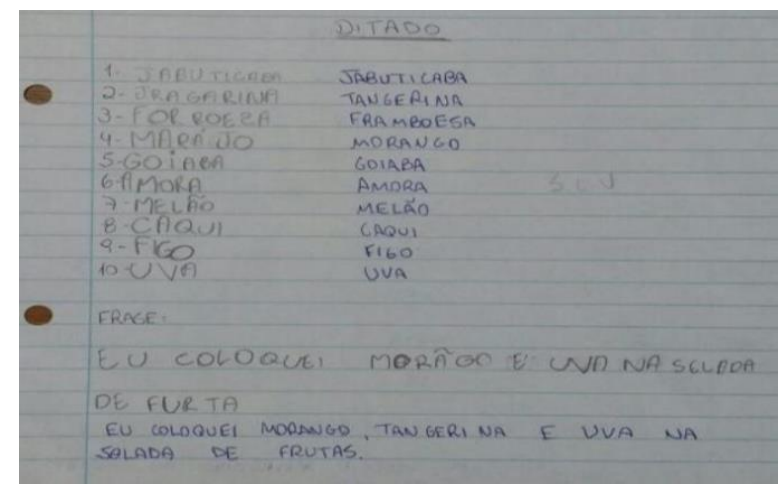

Figura 5 - Avaliação final da escrita.

Fonte: arquivo documental do projeto

A literatura científica (FURTADO, 2004; KISHIMOTO et al., 2011; MACEDO; PETTY; PASSOS, 2005; SANTOS 2011; SILVEIRA, 2004) tem apresentado concepções favoráveis à utilização do jogo, compreendendo-o como um recurso possibilitador de aprendizagens. Tal como afirma Leal et al. (2008), o jogo quando utilizado no ensino da alfabetização, pode tornar este processo mais eficaz e estimulante para o aluno, principalmente para aqueles que já apresentam uma dificuldade, o que implica numa nova prática de ensinar. Além disso, outro 
aspecto relevante em relação à utilização de jogos no período da alfabetização é que estes possibilitam uma postura ativa por parte do estudante em seu processo de aprendizagem, propiciando momentos de reflexão das especificidades do sistema de escrita alfabético, ou seja, estes jogos exigem, por parte da criança, atenção, raciocínio, reflexão, levantamento e verificação de hipóteses acerca da língua escrita.

Mediante ao exposto, acredita-se que projetos de intervenção desse tipo são essenciais porque propiciam aos alunos atendidos formas diferentes de aprender e de trabalhar os conteúdos formais do currículo escolar. Soma-se a isso o fato de que as atividades lúdicas facilitam o trabalho com as dificuldades das crianças, pois as mesmas dificilmente resistem aos desafios impostos, pois os jogos são recursos que mobilizam o interesse, por compor a cultura infantil. Percebe-se aqui que projetos de intervenção agregam conhecimentos e possibilitam fortalecer o vínculo entre alunos e professores, bem como propor iniciativas que efetivamente atendam às necessidades da escola.

Assim, os resultados das avaliações dos alunos participantes do projeto vão ao encontro das pesquisas realizadas sobre o tema, acerca das contribuições dos jogos para o processo de aprendizagem das crianças. Nesse processo, é relevante destacar que somente os jogos, sozinhos, não são capazes de mobilizar os conhecimentos nos alunos, portanto, é fundamental o papel mediador exercido pelas estudantes de Pedagogia, que organizavam as propostas. Assim, o planejamento, a seleção do jogo, a observação do conteúdo trabalhado, os questionamentos e as intervenções durante as jogadas são elementos centrais para a evolução dos alunos.

Desse modo, também se evidencia o processo de formação das alunas da Pedagogia enquanto alfabetizadoras, pois neste processo de atendimento aos alunos, estavam aprendendo a realizar uma avaliação diagnóstica e, a partir desta, compreender quais conteúdos deveriam ser trabalhados e quais eram os meios para atingir os objetivos propostos, isto é, a associação entre os conteúdos e os procedimentos metodológicos, citada por Libâneo (2013). E em específico, o trabalho com os jogos, pois como já se evidenciou, os professores da educação básica ainda citam algumas dificuldades para inserir este recurso em 
seus planejamentos (LUCCA, 2018; SILVEIRA, 2016).

De forma geral, os resultados observados nos atendimentos, juntamente com a avaliação feita pela coordenação pedagógica da escola, que acompanhou os atendimentos, evidenciaram que as crianças atendidas tiveram progresso em sua aprendizagem, e que este progresso apresenta variações uma vez que a característica do grupo atendido era diversa (alunos que não sabiam ler ou escrever e alunos que liam e escreviam com dificuldade). No entanto, ambas as instituições escolares mostraram interesse em que o atendimento realizado fosse postergado, em virtude dos progressos observados nos alunos atendidos.

\section{Considerações finais}

O objetivo principal deste trabalho foi apresentar as ações desenvolvidas em um projeto que atende os alunos do primeiro ciclo do ensino fundamental que não estavam alfabetizados e que apresentavam defasagem na aprendizagem da leitura e escrita. Especificamente, buscou-se inserir a ludicidade como componente do processo de aprendizagem, inserindo os jogos pedagógicos com o objetivo de possibilitar a aquisição do sistema de escrita alfabética e, assim, elaborar outras atividades que contribuíssem para a aprendizagem dos alunos atendidos.

Desse modo, convém destacar a relevância dos jogos de alfabetização utilizados, pois apreende-se que foram ferramentas importantes no processo de aprendizagem dos alunos que apresentavam, de alguma forma, dificuldade em seu processo de aprendizagem. Portanto, pode-se inferir que nesse contexto o jogo, mais do que um divertimento, surge como um instrumento de ensino, uma estratégia diferenciada utilizada com esses estudantes em específico.

Acredita-se que o trabalho aqui realizado efetivamente contribuiu para a aprendizagem dessa pequena parcela de crianças que são atendidas e que, em sua maioria, não recebem qualquer tipo de atendimento individualizado. Assim, uma das contribuições desta pesquisa reside em trazer à tona a discussão, tanto em cursos de formação de professores alfabetizadores, quanto em cursos de graduação em licenciatura, que o jogo pode 
constituir atividade lúdica sistematizada de ensino e que, nesta perspectiva, o jogo não apenas promove atividades lúdicas que proporcionam aos estudantes formas alternativas de aprender e de conviver, mas também permite reconhecer possibilidades para a aprendizagem de conteúdos específicos.

Considera-se que é primordial que discussões sobre os jogos e sua relação com a realidade no contexto escolar torne-se tema nos cursos de formação de professores, seja na formação inicial, seja na formação continuada, já que, conforme apresentado por algumas pesquisas (LUNA, 2008; PIMENTEL, 2005; RITZMANN, 2009; SILVEIRA, 2004), os professores assinalam que não possuem uma formação suficiente para compreender o jogo como um recurso para o processo de aprendizagem. Esses autores (PIMENTEL, 2005; RITZMANN, 2009) ainda indicam que muitos professores não sabem trabalhar com jogos e brincadeiras ou não se interessam por tais ferramentas por desconhecerem sua importância e os modos de inserilos em suas aulas e ressaltam que tal desconhecimento deve-se a uma lacuna em suas formações inicial e continuada nesse assunto, ou seja, em sua formação, o professor não é preparado ou não possui momentos para discutir a importância e a contribuição do lúdico no processo de aprendizagem, bem como para utilizá-lo em sua prática. Portanto, oportunizar, dentro do projeto, o trabalho com a ludicidade traz também benefícios para a formação desses futuros professores, que puderam refletir e construir diversificadas formas de ensino.

Acredita-se que os jogos podem auxiliar nesse processo específico de aprendizagem, ou seja, os jogos, inseridos no processo de ensino-aprendizagem da leitura e escrita, possibilitam o desenvolvimento de habilidades cognitivas necessárias ao sujeito aprendiz. Como foi possível averiguar no acompanhamento do desenvolvimento de uma aluna específica, o recurso jogo atendeu à demanda de aprendizagem da mesma, contribuindo significativamente para seu processo de aprendizagem. Pode-se atribuir esse fato às diversas habilidades precisas e desenvolvidas por meio de jogos e que são também importantes no processo de aprendizagem, tais como a atenção, memória, concentração, descentração do pensamento, habilidades motoras e desenvolvimento da linguagem. Ademais, alguns jogos, dependendo de seus objetivos, além do trabalho com essas habilidades também podem 
envolver outros conteúdos específicos, como no caso de jogos voltados para o processo de alfabetização, o trabalho com as propriedades do Sistema de Escrita Alfabética, essencial para que o indivíduo se torne plenamente alfabetizado, como foi o caso de alguns jogos utilizados no projeto.

Isso posto, convém ainda destacar que os jogos são importantes recursos no processo de aprendizagem devido à relação que instituem com o aprendiz. Isso é, no jogo o sujeito torna-se ativo diante do conteúdo da aprendizagem. Como no caso da aprendizagem da leitura e escrita, em um jogo, o aluno terá uma relação com a linguagem de uma forma dinâmica, ativa, questionadora, inquiridora e com a possibilidade de o erro ser uma oportunidade para a aprendizagem, diferentemente de outras estratégias de ensino, nas quais os sujeitos são passivos e se relacionam com a linguagem como algo distante e, muitas vezes, para os alunos que possuem dificuldades, como algo incompreensivo.

Parte-se da premissa que tanto a escola quanto a universidade devem contribuir para a melhoria da qualidade da educação e, assim, incluir graduandos de pedagogia no cotidiano da escola possibilita a formação de um futuro professor, de modo contextualizado e reflexivo. Além disso, auxilia o professor que já está em sala de aula vivenciando os desafios diários do magistério, possibilitando que este possa compartilhar seus saberes com o estudante e também possa conhecer novos modos de trabalho e novos recursos para a aprendizagem, especialmente no atendimento àqueles alunos que possuem alguma dificuldade.

\section{Referências}

BRASIL. Lei de Diretrizes e Bases da Educação Nacional. Lei número 9394, 20 de dezembro de 1996.

BRASIL. Pacto Nacional pela Alfabetização na Idade Certa. 2013. Disponível em: <http://pacto.mec.gov.br/o-pacto. Acesso em: 24 mar. 2014.

BRASIL. Ministério da Educação. Base nacional comum curricular. Brasília, 2015. Disponível em: <http://basenacionalcomum.mec.gov.br/. Acesso em: 14 maio 2018.

BRASIL. Ministério da Educação. Pacto Nacional pela Alfabetização na Idade Certa. Brasília, 2013. Disponível em: <http://pacto.mec.gov.br/o-pacto. Acesso em: 15 jun. 2014.

BRASIL. Resolução no7, de 22 de março de 2018. Brasília, 2018. Disponível 
em:<https://maisalfabetizacao.caeddigital.net/resources/arquivos/resolucao.pdf $>$. Acesso em: 14 maio 2018.

FERNANDES, T. A.; OSTI, A. O Pacto Nacional pela Alfabetização na Idade Certa e o uso de jogos na aprendizagem inicial da leitura e escrita. Educação em Revista. UNESP, Marília, v. 1, p. 81-98, 2016.

FURTADO, V. Q. Crianças com dificuldade em escrita e estruturação espacial: uma reeducação psicopedagógica. 2004. Tese (Doutorado em Educação) - Universidade Estadual de Campinas, Campinas, 2004.

KISHIMOTO et al. Jogo e letramento: crianças de 6 anos no ensino fundamental. Educ. Pesqui. [online], v. 37, n. 1, p. 191-210, 2011.

KLEIMAN, A. B. Programas de Educação de jovens e adultos e pesquisa acadêmica: a contribuição dos estudos do letramento. Educ. Pesqui. São Paulo, v. 27, n. 2, p. 267-281 jul./dez. 2001.

LIBÂNEO, J. C. Licenciatura em Pedagogia: a ausência de conteúdos específicos do ensino fundamental. In: GATTI, B. A. et al. (org.) Por uma política nacional de formação de professores. Editora Unesp: São Paulo, 2013. p. 73-94.

LEAL, T. F. et al. O lúdico na sala de aula: projetos e jogos. In: Pró-Letramento: alfabetização e linguagem. Brasília: Ministério da Educação, Secretaria da Educação Básica, 2008.

LUNA, F. G. A (in) disciplina em oficina de jogos. 2008. Dissertação (Mestrado em Psicologia Escolar e do Desenvolvimento Humano) Instituto de Psicologia, Universidade de São Paulo, São Paulo, 2008.

LUCCA, T. A. F. A contribuição da formação do PNAIC para a prática de professores alfabetizadores do município de Rio Claro-SP. 2018. Dissertação (Mestrado em Educação Universidade Estadual Paulista, Rio Claro, 2018.

Pesquisa Nacional por Amostra de Domicílios. Disponível em:

<http://g1.globo.com/educacao/noticia/2013/09/indice-de-analfabetismo-para-de-cair-efica-em-87-diz-pnad.html . Acesso em: 05 fev. de 2014.

MACEDO, L.; PETTY, A. L. S.; PASSOS, N. C. O lúdico no processo de desenvolvimento e aprendizagem escolar. Porto Alegre: Artmed, 2005.

MONTEIRO, S. M.; SOARES, M. Processos cognitivos na leitura inicial: relação entre estratégias de reconhecimento de palavras e alfabetização. Educ. Pesqui. São Paulo, v. 40, n. 2, p. 449-466, abr./jun. 2014.

PIAGET, J. Sobre a pedagogia. São Paulo: Casa do Psicólogo, 1998.

SANTOS, K. D. C. O módulo de jogos no Colégio de Aplicação João XXIII: um estudo de caso. 2011. Dissertação (Mestrado em Educação) - Faculdade de Ciências e Tecnologia, Universidade Estadual Paulista, Presidente Prudente, 2011. 
SILVA, E.T. Alfabetização no Brasil: questões e provocações da atualidade. Campinas: Autores Associados, 2007.

SILVEIRA, C. A. F. Os processos inferenciais via jogos de regras na compreensão da leitura. 2004. Dissertação (Mestrado em Educação) - Universidade Estadual de Campinas, Campinas, 2004.

SILVEIRA, M. R. Concepções e práticas docentes sobre o brincar em sala de aula no primeiro ano do Ensino Fundamental. 2016. Dissertação (Mestrado em Educação) Universidade de São Paulo, Ribeirão Preto, 2016.

SOARES, M. Letramento e Alfabetização: as muitas facetas. Rev. Bras. Educ. n. 25, p. 5-17, 2004.

SUBA, L. A. O ensino da leitura e da escrita: uma questão que perpassa a formação do pedagogo. 2012. Dissertação (Mestrado em Comunicação e Artes) - Universidade Estadual de Londrina, Londrina, 2012. 